\title{
SALSICHAS TIPO HOT DOG: PERFIL MICROBIOLÓGICO, ISOLAMENTO E CARACTERIZAÇÃO DE BACTÉRIAS ÁCIDO LÁTICAS (BAL) COM POTENCIAL ANTAGONISTA
}

Ivan de Marco ${ }^{1}$, Cristine Vogel ${ }^{1}$, Gisiéli Carla Morandin ${ }^{1}$, Luniele Beilke ${ }^{1}$, Natália Zini Valduga ${ }^{2}$, Eliziane Tais Zambiazi ${ }^{2}$, Julia Villain Martinhago ${ }^{2}$ e Liziane Schittler ${ }^{3}$

${ }^{1}$ Universidade do Estado de Santa Catarina, Departamento de Engenharia de Alimentos, Mestrando(a) em Ciência e Tecnologia de Alimentos

${ }^{2}$ Universidade do Estado Santa Catarina, Departamento de Engenharia de Alimentos, Graduanda em Engenharia de Alimentos

${ }^{3}$ Universidade do Estado de Santa Catarina, Departamento de Ciência e Tecnologia de Alimentos, Doutora em Ciência e Tecnologia Agroindustrial

E-mail para contato: ivandemarco22@gmail.com

RESUMO - A salsicha é o produto cárneo mais consumido, no entanto, este produto pode apresentar alto risco de contaminação, devido a sua excessiva manipulação durante a produção e comercialização. Este trabalho teve como objetivo, avaliar o perfil microbiológico de duas marcas de salsichas, comercializadas em embalagens a vácuo e a granel, bem como isolar bactérias ácido láticas (BAL) com atividade antagonista. Para isto, as salsichas foram submetidas as contagens de micro-organismos mesófilos, psicrotróficos, enterobactérias, BAL, bolores e leveduras, coliformes termotolerantes, Staphylococcus coagulase positiva e pesquisa de Salmonella spp.. As maiores contagens de microorganismos mesófilos, psicrotróficos, enterobactérias e Staphylococcus coagulase positiva foram obtidas em salsichas comercializadas a granel. Não foi identificado a presença de Salmonella spp.. Isolou-se $15 \mathrm{BAL}$, dentre estas, quatro apresentaram atividade antagonista contra a pelo menos um, dos micro-organismos testados (Listeria monocytogenes, Salmonella Enteretidis, Bacillus cereus e Escherichia coli). Os quatro isolados de BAL foram sensíveis aos antibióticos ampicilina, penicilina, vancomicina e tetraciclina, o que qualifica para ser utilizado em alimentos. O perfil microbiano da salsicha é variável, está diretamente relacionada com a qualidade na produção e comercialização do produto. As BAL isoladas de salsicha apresentam atividade antagonista contra micro-organismo patogênicos.

Palavras-chave: Bacteriocinas. Condições Higiênico-sanitárias. Atividade Antimicrobiana.

DOI: $10.5965 / 24473650412018149$ 
Recebido em:

$13 / 09 / 2018$

Aceito em:

$19 / 12 / 2018$

\section{INTRODUÇÃO}

Os produtos cárneos processados são amplamente consumidos por ser uma ótima fonte de proteína. Dentre os produtos cárneos, a salsicha tipo hot dog destaca-se, por sua praticidade, como um dos mais populares. As salsichas são comercializadas nos supermercados em embalagens de propileno termoencolhível (vácuo) bem como a granel. A comercialização de salsicha a granel possibilita o aumento da contaminação microbiana, devido à manipulação excessiva e o acondicionamento em embalagens não apropriadas, o que acarreta risco a saúde do consumidor, além de reduzir o prazo de validade do produto (BAÚ et al., 2012).No entanto, este produto chama atenção dos consumidores, devido ao seu baixo custo quando comparado com as salsichas comercializadas em embalagens a vácuo.

De acordo com Costa (2008), os alimentos são passiveis de contaminação e os principais micro-organismos patogênicos que oferecem risco a saúde do consumidor são Salmonella spp. Staphylococccus coagulase positiva, Clostridium botulinum, Clostridium perfringens, Bacillus cereus e Listeria monocytogene ou até mesmos por suas toxinas. Essas bactérias podem provocar inúmeras doenças, conhecidas como DTAs (Doenças Transmitidas por Alimentos).

Os produtos cárneos de modo geral, podem ser facilmente deteriorados por apresentar características intrínsecas, como nutrientes, atividade de água e $\mathrm{pH}$ favoráveis. Os principais microorganismos responsáveis pela deterioração destes produtos são os psicrotróficos, bolores e leveduras e bactérias ácido láticas (SADE, 2011).

As bactérias ácido láticas (BAL) são encontradas naturalmente em muitos produtos cárneos, como a salsicha, e podem causar a deterioração, que se caracteriza pelas modificações organolépticas do produto (VERCAMMEN et al., 2011). Entretanto, as BAL podem apresentar atividade antagonista contra micro-organismos indesejáveis, o que permite uma importante perspectiva tecnológica na utilização desses micro-organismos na conservação e controle de patógenos em alimentos. A atividade antimicrobiana das BAL, se deve a produção de ácido láctico, dióxido de carbono, ácido acético, etanol, acetato, peróxido de hidrogênio e as bacteriocinas (FERNANDES et al., 2015; GASPAR et al., 2013).

Em alimentos, as BAL podem ser adicionadas a matéria-prima, e durante o processo de fermentação, as mesmas produzem as substâncias antimicrobianas, desta forma, agindo como bioprotetor. No entanto, sua aplicação apresenta restrições em alimentos não fermentados e/ou que passam por processos com altas temperaturas. Já, a utilização das bacteriocinas em alimentos apresentam algumas vantagens. As bacteriocinas são peptídeos catiônicos antibacterianos, termoestáveis, sensibilidade as enzimas digestivas, desta forma, não interferem na microbiota intestinal (MESSAOUDI et al., 2013; PEHRSON, 2013; LIMA et al., 2003). Além, de que as bacteriocinas apresentam atividade antimicrobiana contra vários micro-organismos Gramnegativos e Gram-positivos oportunistas ou patogênicos de importância em alimentos.

Para a utilização de novos isolados de BAL em alimentos, se faz necessário avaliar a presença de mecanismos de virulência como, a sensibilidade a antibióticos clínicos. Bactérias resistentes aos antibióticos clínicos podem transferir genes de resistência a outros micro-organismos como os iniciadores, patogênicos e deteriorantes de importância para indústria alimentícia (D'AIMMO et al., 2007). 
Recebido em:

$13 / 09 / 2018$

Aceito em:

$19 / 12 / 2018$

Devido ao exposto, este trabalho teve como objetivo avaliar o perfil microbiológico de duas marcas de salsichas, comercializadas em embalagens a vácuo e a granel, bem como isolar bactérias ácido láticas com potencial atividade antagonista.

\section{MATERIAL E MÉTODOS}

\subsection{Análises microbiológicas}

Foram adquiridas salsichas suína, tipo hot dog de duas marcas comercializadas em dois supermercados em embalagem de polietileno (vácuo) e a granel, em um município do oeste de Santa Catarina, Brasil. Realizou-se três coletas, com intervalos de 15 dias, totalizando 24 amostras.

As amostras foram acondicionadas em caixas isotérmicas com gelo e transportadas ao laboratório de Microbiologia de Alimentos e Biologia Molecular do Departamento de Engenharia de Alimentos e Engenharia Química, da Universidade do Estado de Santa Catarina.

As salsichas foram submetidas as análises microbiológicas de contagens de mesófilos, psicrotróficos, enterobactérias, bactérias ácido láticas, bolores e leveduras, Staphylococcus coagulase positiva, Número Mais Provável (NMP) de coliformes termotolerantes $\left(45^{\circ} \mathrm{C}\right)$ e pesquisa de Salmonella spp.

Pesou-se assepticamente $25 \mathrm{~g}$ de salsicha em sacos estéreis tipo stomacher e adicionou-se $225 \mathrm{~mL}$ de água peptonada a $0,1 \%(\mathrm{p} / \mathrm{v})$, perfazendo a diluição $10^{-1}$. A partir desta diluição, preparou-se as demais diluições seriadas.

Para as contagens de micro-organismos mesófilos aeróbios e psicrotróficos, utilizou-se o método descrito pela ISO 4833:2013 e APHA: 2015, respetivamente. Alíquotas de $1 \mathrm{~mL}$ e 0,1 mL foram inoculadas em Ágar Plate Count Agar (PCA/Merck) e incubadas a $30{ }^{\circ} \mathrm{C} \mathrm{e} 7{ }^{\circ} \mathrm{C}$, por $72 \mathrm{~h} \mathrm{e}$ 10 dias, respectivamente. As colônias foram contadas e o resultado expresso em log. UFC. $\mathrm{g}^{-1}$.

As contagens de enterobacterias e de bactérias ácido láticas foram realizadas de acordo com ISO 21528-2:2017 e ISO 15214:1998, respectivamente. Inoculou-se em profundidade 1mL das diluições selecionadas em placas de Petri e adicionou-se o ágar Violet Red Bile Glucose (VRBG/Oxoid) e ágar Man, Rogosa and Sharpe (MRS/Oxoid), as quais foram incubadas $37^{\circ} \mathrm{C}$ por $24 \mathrm{~h}$ e $72 \mathrm{~h}$, respectivamente. As placas que apresentaram colônias foram contadas e o resultado foi expresso em log. UFC. $\mathrm{g}^{-1}$.

A contagem de bolores e leveduras foi realizada de acordo com a Instrução normativa IN n $^{\circ}$ 62 do Ministério da Agricultura Pecuária e Abastecimento - MAPA (BRASIL, 2003). Inoculou-se $0,1 \mathrm{~mL}$ das diluições selecionadas em placas contendo Ágar Batata Dextrose (BD/Oxoid). Incubouse a $25{ }^{\circ} \mathrm{C}$, por 5 a 7 dias. As colônias foram contadas e o resultado expresso em log. UFC. $\mathrm{g}^{-1}$.

A contagem de Staphylococcus coagulase positiva foi realizada de acordo com IN n ${ }^{\circ} 62$ do MAPA (BRASIL, 2003). Inoculou-se $0,1 \mathrm{~mL}$ das diluições selecionadas em placas contendo Ágar Baird-Parker (BP/Oxoid), e incubou-se a $35^{\circ} \mathrm{C}$, por $48 \mathrm{~h}$. As colônias negras foram submetidas aos testes bioquímicos de coagulase e catalase.

Para determinar o NMP de coliformes termotolerantes, alíquotas de $1 \mathrm{~mL}$ das diluições $10^{-1}$ $10^{-2}, 10^{-3}$ foram transferidas para uma série de três tubos contendo Caldo Lauril Triptose (LST/Oxoid) e tubos de Durhan. Incubou-se a $35^{\circ} \mathrm{C}$ por $48 \mathrm{~h}$. Tubos com turvação e presença de gás, foram submetidos a confirmação de presença de coliformes termotolerantes. Transferiu-se 
Recebido em:

$13 / 09 / 2018$

Aceito em:

$19 / 12 / 2018$

uma alçada de cada tubo positivo, para caldo Escherichia coli (EC/Oxoid) e incubou-se a $45^{\circ} \mathrm{C}$, por $48 \mathrm{~h}$. Utilizou-se a tabela do NMP. $\mathrm{g}^{-1}$ com intervalo de confiança de $95 \%$ para expressar os resultados.

Utilizou-se a ISO 6579:2002 para pesquisa Salmonella spp. O pré-enriquecimento foi realizado com $25 \mathrm{~g}$ de salsicha em $225 \mathrm{~mL}$ de água peptonada tamponada (Merk) e incubou-se $37^{\circ} \mathrm{C}$ por $18 \mathrm{~h}$. Para o enriquecimento seletivo, transferiu-se alíquotas de $0,1 \mathrm{~mL}$ e $1 \mathrm{~mL}$ para caldo Rappaport Vassiliadis (RV/Difco) e Muller-Kauffmann (MK/Difco) e incubou-se a $41,5{ }^{\circ} \mathrm{C}$ e $37{ }^{\circ} \mathrm{C}$, respectivamente por $24 \mathrm{~h}$. Repicou-se as amostras para Ágar Xilose Lisina Desoxicolato (XLD/Oxoid) e Ágar Verde Brilhante (AVB/Oxoid) e incubou-se a $37^{\circ} \mathrm{C}$ por $24 \mathrm{~h}$. As colônias típicas obtidas nas placas foram confirmadas através de testes de descarboxilação da lisina, fermentação da lactose e/ou sacarose e produção de $\mathrm{H}_{2} \mathrm{~S}$, no Ágar Lisina Ferro (Merk) e Ágar Tríplice Açúcar Ferro (Merk).

\subsection{Avaliação da atividade antagonista de isolados de BAL}

A partir das placas de MRS obtidas para contagens de BAL, colônias foram aleatoriamente selecionadas por amostra, transferindo-as para caldo MRS e incubadas a $35^{\circ} \mathrm{C}$ por $24 \mathrm{~h}$. Para fins de purificação, alçadas das amostras crescidas em caldo foram estriadas em ágar MRS e incubadas a $35{ }^{\circ} \mathrm{C}$ por $48 \mathrm{~h}$. Em seguida, uma colônia isolada de cada cultura foi transferida para tubos contendo caldo MRS (Oxoid) $\left(35^{\circ} \mathrm{C}\right.$ por $24 \mathrm{~h}$ ) e posteriormente estriadas em ágar Tripticase de Soja (TSA/Oxoid) e mantidas sob refrigeração.

Utilizou-se a técnica spot-on-the-lawn, adaptada de Fleming et al. (1975) para verifica a atividade antagonista das BAL. Os isolados de BAL foram recuperados em caldo MRS (Oxoid), e incubados a $25^{\circ} \mathrm{C}$, por $24 \mathrm{~h}$. Alíquotas de $2 \mu \mathrm{L}$ das culturas foram inoculadas em ágar MRS e incubadas a $35^{\circ} \mathrm{C}$ por $24 \mathrm{~h}$. Após, adicionou-se uma sobrecamada de $8 \mathrm{~mL}$ de ágar semi-sólido de Infusão de Cérebro e Coração (BHI), contendo os micro-organismos reveladores, Salmonella Enteretidis ATCC 13076 e Listeria monocytogenes Scott A, Bacillus cereus CCCD B001 e Escherichia coli ATCC 25922, na concentração de $10^{5}$ UFC. $\mathrm{mL}^{-1}$. Incubou-se a $35^{\circ} \mathrm{C}$ por $24 \mathrm{~h}$. A presença de halos de inibição em torno da cultura, foi considerado positivo para a presença de substância antagonista. Os halos foram medidos e os valores expressos em milímetros.

Os isolados de BAL que apresentaram atividade antagonista no ágar MRS foram submetidos a confirmação da atividade bactericinogênica. Recuperou-se os isolados em caldo MRS, à $25^{\circ} \mathrm{C}$ por $24 \mathrm{~h}$. Transferiu-se três alíquotas de $2 \mu \mathrm{L}$ de cada cultura para placa contendo $10 \mathrm{~mL}$ de ágar MRS modificado $\left(0,5 \%\right.$ de dextrose). Incubou-se a $25{ }^{\circ} \mathrm{C}$ por $24 \mathrm{~h}$, em anaerobiose. Após, foram feitos orifícios de $3 \mathrm{~mm}$ de diâmetro no ágar, a $0,5 \mathrm{~cm}$ de distância de cada crescimento, e adicionou-se $20 \mu \mathrm{L}$ das enzimas: pepsina (de mucosa de estômago de suíno), $\alpha$-quimotripsina (de pâncreas de bovino), proteinase K (de Tritirachium album), e tripsina (de pâncreas bovino). Como controle negativo, utilizou-se água destilada esterilizada. Após $15 \mathrm{~min}$ em temperatura ambiente, adicionou-se uma sobrecamada de $8 \mathrm{~mL}$ de BHI semi-sólido, contendo a concentração de $10^{5}$ UFC. $\mathrm{mL}^{-1}$ dos micro-organismos reveladores. Incubou-se a $35^{\circ} \mathrm{C}$ por $24 \mathrm{~h}$. A confirmação da produção de bacteriocinas se dá, através da sensibilidade da substância produzida por uma ou mais enzimas testadas. Quando a substância é sensível as enzimas ocorre o crescimento do micro-organismo revelador onde a enzima foi aplicada, formando um halo em forma de meia lua em volta da cultura. 


\subsection{Sensibilidade à antibióticos clínicos}

A sensibilidade a antimicrobianos dos isolados de BAL foi avaliada através do método de difusão em ágar Mueller-Hinton (MH/Merck), conforme descrito por Renye et al. (2009). Testouse quatro diferentes antibióticos: ampicilina $(10 \mu \mathrm{g})$, penicilina $\mathrm{G}(10 \mu \mathrm{g})$, vancomicina $(30 \mu \mathrm{g}) \mathrm{e}$ tetraciclina $(30 \mu \mathrm{g})($ Laborclin/ Brasil).

Os isolados foram recuperados em caldo MRS a $35^{\circ} \mathrm{C}$ por $24 \mathrm{~h}$. A concentração bacteriana foi ajustada através do auxílio da escala 0,5 de MacFarland $\left(3 \times 10^{8}\right.$ UFC. $\left.\mathrm{mL}^{-1}\right)$. Inoculou-se 0,1 $\mathrm{mL}$ das culturas na superfície do ágar Mueller-Hinton (MH/Merck). Adicionou-se os discos dos antibióticos e incubou-se a $35{ }^{\circ} \mathrm{C}$ por $24 \mathrm{~h}$. Os diâmetros das zonas de inibição formados foram medidos com auxílio de paquímetro, e os valor expresso em milímetro. Os isolados foram considerados resistente (R), sensibilidade intermediária (I) ou sensível (S), com base nos valores de referências indicados pela Clinical and Laboratory Standards Institute-CLSI (Tabela 1).

Tabela 1 - Tamanho dos halos de inibição (mm) para classificação de BAL como Resistente (R), Intermediário (I) e Sensível (S) para os antimicrobianos Ampicilina (10 ug), Penicilina (10 ug), Vancomicina (30 ug) e Tetraciclina (30 ug).

\begin{tabular}{cccc}
\hline & \multicolumn{3}{c}{ Halos de inibição $(\mathrm{mm})$} \\
\hline Antibiótico & Resistente $(\mathrm{R})$ & Intermediário $(\mathrm{I})$ & Sensível $(\mathrm{S})$ \\
\hline Ampicilina $10 \mu \mathrm{g}$ & $<13$ & $14-16$ & $>17$ \\
Penicilina $10 \mu \mathrm{g}$ & $<14$ & - & $>15$ \\
Vancomicina 30 $\mu \mathrm{g}$ & $<14$ & $16-16$ & $>15$ \\
Tetraciclina 30 $\mu \mathrm{g}$ & $<14$ & $15-18$ & $>19$ \\
\hline
\end{tabular}

Fonte: Clinical and Laboratory Standards Institute -CLSI (2018)

\subsection{Análise Estatística}

As contagens de micro-organismos mesófilos, psicrotróficos, enterobactérias, BAL, bolores e leveduras, Staphylococcus coagulase positiva em salsicha, bem como os halos de inibição produzidos pelas BAL contra os micro-organismos reveladores foram submetidos a análise de variância (ANOVA), e as médias comparadas pelo teste de Tukey, com intervalo de confiança de 95\% ( $\mathrm{p}<0,05)$, utilizando software Statistica versão 10.0.

\section{RESULTADOS E DISCUSSÃO}

\subsection{Análises Microbiológicas}

As médias das contagens de mesófilos, psicrotróficos, enterobactérias, BAL, bolores e leveduras e Staphylococcus coagulase positiva realizadas em salsichas comercializadas nos dois supermercados em embalagens a vácuo e a granel encontram-se nas tabelas 2 e 3. 
Recebido em:

$13 / 09 / 2018$

Aceito em:

$19 / 12 / 2018$

Tabela 2: Médias das contagens de micro-organismos mesófilos, psicrotróficos e enterobactérias $\left(\log\right.$ UFC. $\left.g^{-1}\right)$

\begin{tabular}{lccc}
\hline & Mesófilos & Psicrotróficos & Enterobactérias \\
\hline VA2 & $2,57 \pm 0,99^{\mathrm{bc}}$ & $2,00 \leq 0,01^{\mathrm{b}}$ & $2,33 \pm 0,58^{\mathrm{ab}}$ \\
VB2 & $2,33 \pm 0,58^{\mathrm{c}}$ & $2,00 \leq 0,01^{\mathrm{b}}$ & $2,00 \leq 0,01^{\mathrm{d}}$ \\
VA1 & $2,57 \pm 0,98^{\mathrm{bc}}$ & $2,00 \leq 0,01^{\mathrm{b}}$ & $2,04 \pm 0,64^{\mathrm{b}}$ \\
VB1 & $2,72 \pm 0,63^{\mathrm{bc}}$ & $2,00 \leq 0,01^{\mathrm{b}}$ & $2,11 \pm 0,20^{\mathrm{ab}}$ \\
GA2 & $6,08 \pm 1,28^{\mathrm{ab}}$ & $7,63 \pm 0,50^{\mathrm{a}}$ & $4,87 \pm 1,17^{\mathrm{a}}$ \\
GB2 & $7,58 \pm 0,73^{\mathrm{a}}$ & $7,60 \pm 0,86^{\mathrm{a}}$ & $3,75 \pm 1,86^{\mathrm{ab}}$ \\
GA1 & $6,44 \pm 2,17^{\mathrm{a}}$ & $8,20 \pm 0,23^{\mathrm{a}}$ & $4,57 \pm 1,43^{\mathrm{ab}}$ \\
GB1 & $6,99 \pm 1,72^{\mathrm{a}}$ & $8,10 \pm 0,36^{\mathrm{a}}$ & $4,47 \pm 0,78^{\mathrm{ab}}$ \\
\hline
\end{tabular}

Médias seguidas de mesma letra não diferem estatisticamente entre si, minúscula na coluna, pelo teste de Tukey $(\mathrm{p}>0,05)$. V- Salsicha embalada a vácuo; G- Salsicha a granel; A e B - Marcas de salsicha; 1 e 2 - Supermercados.

Fonte: elaborado pelos autores (2018)

Os mesófilos são micro-organismos que se desenvolvem em temperaturas entre $10{ }^{\circ} \mathrm{C}$ e 45 ${ }^{\circ} \mathrm{C}$, considerados os principais contaminantes de alimentos de origem animal. As quantidades destes micro-organismos podem ser utilizadas como indicativo de qualidade do produto (SAEKI; MATSUMOTO, 2010).

As médias das contagens de mesófilos nas salsichas comercializadas em dois supermercados, em embalagem a vácuo e a granel, variaram entre 2,33 e 7,58 log. UFC. $\mathrm{g}^{-1}$ (tabela 2). As menores contagens de mesófilos foram obtidas em salsichas comercializadas em embalagem a vácuo, que variaram entre 2,33 e 2,72 log. UFC. $\mathrm{g}^{-1}$. Não houve diferença estatística $(\mathrm{p}>0,05)$ nas contagens de mesófilos nas salsichas comercializadas a vácuo entre os dois supermercados.

Resultados diferentes foram relatados por Ferraccioli (2012), onde as contagens de mesófilos em salsichas processadas e embaladas a vácuo variaram entre 1,00 e 3,70 log. UFC. g-1. Já, resultados superiores foram observados por Diniz e Lago (2016), onde realizaram contagem de mesófilos em presuntos embalados a vácuo e obtiveram contagens entre 2,38 a 6,20 log. UFC. $\mathrm{g}^{-1}$. A diferença nos resultados encontrados em nosso estudo e Ferraccioli (2012), pode ser explicado por diversos fatores, entre eles, as condições do processamento, bem como a temperatura de refrigeração.

Pode-se verificar na Tabela 2, que as maiores contagens de micro-organismos mesófilos foram obtidas em salsichas comercializadas a granel, variaram entre 6,08 e 7,58 log. UFC. $\mathrm{g}^{-1}$. Este resultado já era esperado, devido à manipulação excessiva do produto durante a comercialização.

A média das contagens de micro-organimos psicrotróficos nas salsichas comercializadas a vácuo e a granel, nos dois supermercados do oeste de Santa Catarina, variaram entre 2,00 e 8,20 log. UFC. $\mathrm{g}^{-1}$ (tabela 2). Não houve diferença estatística $(\mathrm{p}>0,05)$ nas contagens de psicrotróficos entre as salsichas comercializadas em embalagem a vácuo.

Resultados diferentes foram relatados por Carvalho (2005) onde obtiveram contagem de micro-organismos psictrotróficos entre 1 e 2 log. UFC. $\mathrm{g}^{-1} \mathrm{em}$ salsichas de frango comercializadas a granel. 
Recebido em:

$13 / 09 / 2018$

Aceito em:

$19 / 12 / 2018$

A diferença de resultados entre nosso estudo e Carvalho (2005) pode ser explicado, pela temperatura de armazenamento bem como as condições de higiene e manipulação deste produto, que pode variar no ponto de comercialização.

Observa-se na tabela 2, que a maioria das salsichas comercializadas a granel apresentam contagens próximas a $8,00 \mathrm{log}$. UFC. $\mathrm{g}^{-1}$ para psicotróficos. Embora, não haja legislação que preconize limite máximo de contagem para psicrotróficos, Champagne et al. (1994), relatam que valores acima de 6,00 log. UFC. $\mathrm{g}^{-1}$, é possível perceber alterações organolépticas nos alimentos.

Desta forma, todas as salsichas comercializadas a granel avaliadas neste estudo, podem apresentar alterações organolépticas perceptíveis. Estas alterações organolépticas nos alimentos se deve a multiplicação e produção de enzimas lipolíticas e proteolíticas termorresistentes pelos psicrotróficos (OLIVEIRA, 2012).

A família das enterobactérias engloba muitos gêneros, a contagem dos mesmos é usada como um indicador da qualidade higiênico-sanitária dos alimentos (VALENTE, 2017).

As menores contagens de enterobactérias foram obtidas em salsichas comercializadas em embalagens a vácuo, que variaram entre 2,00 e 2,33 log. UFC. $\mathrm{g}^{-1}$. Já as contagens de enterobactérias em salsichas comercializadas a granel variaram entre 3,75 e 4,87 log. UFC.g ${ }^{-1}$.

No estudo realizado por Sousa et al. (2016) com produtos de charcutaria, cárneos cozidos e fatiados em talhos, obtiveram a contagens de enterobactérias de $<3$ log. UFC. $\mathrm{g}^{-1}$ em $100 \%$ dos produtos.

Tabela 3: Médias das contagens de BAL, Bolores e Leveduras e Staphylococcus coagulase positiva (log. UFC. $\left.\mathrm{g}^{-1}\right)$

\begin{tabular}{cccc}
\hline & BAL & Bolores e leveduras & S. coagulase positiva \\
\hline VA2 & $2,60 \pm 1,05^{\mathrm{b}}$ & $3,14 \pm 1,97^{\mathrm{ab}}$ & $2,00 \leq 0,01^{\mathrm{b}}$ \\
VB2 & $2,30 \pm 0,30^{\mathrm{b}}$ & $2,00 \leq 0,01^{\mathrm{b}}$ & $2,00 \leq 0,01^{\mathrm{b}}$ \\
VA1 & $2,43 \pm 0,75^{\mathrm{b}}$ & $2,14 \pm 0,24^{\mathrm{b}}$ & $2,00 \leq 0,01^{\mathrm{b}}$ \\
VB1 & $2,49 \pm 0,85^{\mathrm{b}}$ & $2,00 \leq 0,01^{\mathrm{b}}$ & $2,00 \leq 0,01^{\mathrm{b}}$ \\
GA2 & $5,34 \pm 1,59^{\mathrm{ab}}$ & $5,36 \pm 1,85^{\mathrm{ab}}$ & $3,79 \pm 0,52^{\mathrm{a}}$ \\
GB2 & $6,69 \pm 2,40^{\mathrm{a}}$ & $4,12 \pm 0,86^{\mathrm{ab}}$ & $3,33 \pm 0,76^{\mathrm{a}}$ \\
GA1 & $6,04 \pm 1,88^{\mathrm{ab}}$ & $7,12 \pm 3,16^{\mathrm{a}}$ & $3,56 \pm 0,66^{\mathrm{a}}$ \\
GB1 & $5,19 \pm 1,61^{\mathrm{ab}}$ & $4,43 \pm 1,49^{\mathrm{ab}}$ & $2,75 \pm 0,65^{\mathrm{ab}}$ \\
\hline
\end{tabular}

Médias seguidas de mesma letra não diferem estatisticamente entre si, minúscula na coluna, pelo teste de Tukey $(\mathrm{p}>0,05)$. V - Salsicha em embalagem a vácuo; G- Salsicha a granel; A e B - Marcas de salsicha; 1 e 2 - Pontos venda.

Fonte: elaborado pelos autores (2018).

Pode-se observar na tabela 3 , que as médias das contagens de BAL em salsichas comercializadas em embalagens a vácuo e a granel variaram entre 2,30 e 6,69 log. UFC. $\mathrm{g}^{-1}$. Mostrando como as maiores contagens de BAL foram obtidas nas salsichas comercializadas a granel, independente do supermercado. No entanto, as contagens de BAL não diferem estatisticamente entre as salsichas comercializadas em embalagens vácuo e a granel, com exceção a salsicha GB2.

Segundo Nobre (2011), embora as BAL sejam micro-organismos deteriorantes, a sua presença em alimentos pode reduz a quantidade de bactérias patogênicas, devido estes organismos 
Recebido em:

$13 / 09 / 2018$

Aceito em:

$19 / 12 / 2018$

produzirem metabólitos antimicrobianos como ácido lático, peróxido de hidrogênio ou até mesmo bacteriocinas.

As menores contagens de bolores e leveduras obtidas (tabela 3), foi de 2,00 log. UFC. G ${ }^{-1}$ em salsichas comercializadas em embalagem a vácuo, de mesma marca, nos dois supermercados (VB2 e VB1). Enquanto que a maior contagem de bolores e leveduras foi de 7,12 log. UFC. G-1, em salsicha comercializada a granel (GA1). Houve diferença significativa $(p>0,05)$ nas contagens de bolores e leveduras entre a salsicha comercializada a granel (GA1) e as salsichas comercializadas em embalagem a vácuo (VB2, VA1 e VB1). As salsichas das duas marcas, comercializadas a granel, nos dois supermercados, não apresentaram diferença estatística entre si $(\mathrm{p}>0,05)$ nas contagens de bolores e leveduras.

Assim como outros micro-organismos avaliados neste estudo, os bolores e leveduras podem fornecer informações sobre as condições higiênicas de equipamentos, manipuladores bem como falhas no processamento e/ou estocagem (SILVA, 2002).

Resultados diferentes foram relatados por Cunha et al. (2017), que avaliaram quatro diferentes marcas de salsicha tipo hot dog, comercializadas em embalagens a vácuo, em dois municípios goianos, nas quais, não houve multiplicação de bolores e leveduras. Contagens inferiores foram encontradas em estudo de Ehrampoush et al. (2017), onde avaliaram a qualidade microbiológica de salsicha pré-cortada e pós-cortada no varejo do Irã e obtiveram contagens entre 0,92 e 1,47 log. UFC. $\mathrm{g}^{-1}$ para bolores e leveduras, respectivamente. O Irã preconizado o limite máximo de 2 log. UFC. $\mathrm{g}^{-1}$ de bolores e leveduras. Se considerarmos o padrão estabelecido pelo Irã, 75\% das salsichas avaliadas neste estudo, estariam em desacordo com a legislação.

$\mathrm{Na}$ tabela 3, pode-se verificar as médias das contagens de $S$. coagulase positiva nas salsichas comercializadas a vácuo foram menores que 2,00 $\log$. UFC. $\mathrm{g}^{-1}$. Já as contagens de $S$. coagulase positiva em salsichas comercializadas a granel, variaram entre 2,75 e 3,79 log. UFC. $\mathrm{g}^{-1}$. De acordo com a Resolução RDC n ${ }^{\circ} 12$, estabelece o limite máximo de até 3,48 log. UFC. $\mathrm{g}^{-1}$ de $S$. coagulase positiva para salsicha. As salsichas comercializadas a granel de mesma marca, porém, de supermercados diferentes (GA1 e GA2), apresentaram contagens de $S$. coagulase positiva acima dos padrões estabelecidos pela legislação. Este resultado demostra, que a contaminação por $S$. coagulase positiva ocorreu durante o processo fracionamento da salsicha no supermercado.

Resultados superiores foram relatados por Alcântara, Gatto, Andreani (2012), onde avaliaram salsichas embaladas a vácuo e a granel, de diferentes estabelecimentos, e obtiveram contagens de $S$. coagulase positiva de 2,00 e de $7,66 \log$. UFC. $\mathrm{g}^{-1}$, respectivamente. Para as embaladas a vácuo, os resultados mostram-se semelhantes a este trabalho, evidenciando mais uma vez que a contaminação está extremamente relacionada com a conduta durante a manipulação, processamento e/ou armazenagem e comercialização deste produto.

Quanto aos coliformes termotolerantes, das 24 amostras de salsicha avaliadas, três amostras da marca A (12,5\%), comercializadas a granel, apresentaram níveis de coliformes termotolerantes de 4,04 log NMP.g ${ }^{-1}$, acima do permitido pela RDC $\mathrm{n}^{\circ} 12$ (BRASIL, 2001), que determina o máximo de 3,00 log. NMP. $\mathrm{g}^{-1}$.

No grupo dos coliformes termotolerantes, aqueles capazes de fermentar a lactose em temperatura de $45^{\circ} \mathrm{C}$, podemos encontrar a Escherichia coli, tendo como principal habitat o trato intestinal de humanos e de animais de sangue quente, esta, é subdividido em vários biótipos e sorotipos e alguns destes são patogênicos em grande potencial para o homem (ALCÂNTARA; GATTO; ANDREANI, 2012). 
Recebido em:

$13 / 09 / 2018$

Aceito em:

$19 / 12 / 2018$

Contagens superiores foram relatados por Alcântara, Gatto, Andreani (2012) em salsichas comercializadas a granel e obtiveram contagem de 6,51 log. UFC. $\mathrm{g}^{-1}$ de coliformes termotolerantes

Quando comparamos as duas categorias de comercialização, em embalagem a vácuo e a granel, é possível notar que, a qualidade do produto está inteiramente relacionada a excessiva manipulação durante a comercialização.

Em todas as salsichas comercializadas a vácuo ou a granel (100\%) não foi identificada a presença de Salmonella spp., estando de acordo com a legislação, que determina ausência deste micro-organismo em $25 \mathrm{~g}$ do alimento (BRASIL, 2001). Diferentes resultados foram relatados por Alcantra, Gatto e Andreani (2012), onde foi identificada a presença de Salmonella spp. em 50\% das salsichas comercializadas a granel.

\subsection{Avaliação da atividade bacteriocinogênica de isolados de BAL}

Dos 15 isolados de BAL de salsicha embaladas a vácuo e a granel, quatro $(26,66 \%)$ apresentaram atividade antagonista contra a pelo menos um dos micro-organismos patogênicos testados. Os quatro isolados com atividade antagonista são oriundos de salsicha comercializada a granel (tabela 4).

Tabela 4: Médias do tamanho dos halos de inibição $(\mathrm{mm})$ produzidos pelos isolados de BAL (S 7, S 12, S 13, S 14) contra L. moncytogenes, S. Enteretidis, B. cereus e E. coli.

\begin{tabular}{lcccc}
\hline & S 07 & S 12 & S 13 & S 14 \\
\hline L. monocytogenes & $21,75 \pm 1,70^{\mathrm{aA}}$ & $18,75 \pm 3,80^{\mathrm{aA}}$ & $20,75 \pm 2,40^{\mathrm{aB}}$ & $19,00 \pm 4,90^{\mathrm{aA}}$ \\
S. Enteretidis & $18,00 \pm 2,10^{\mathrm{aA}}$ & $12,25 \pm 1,70^{\mathrm{abA}}$ & $11,50 \pm 2,10^{\mathrm{abC}}$ & $8,25 \pm 0,30^{\mathrm{bB}}$ \\
B. cereus $^{\text {E. coli }}$ & $15,00 \pm 4,20^{\mathrm{aA}}$ & $10,25 \pm 0,30^{\mathrm{aA}}$ & $12,25 \pm 0,30^{\mathrm{aC}}$ & $7,50 \pm 0,70^{\mathrm{aB}}$ \\
\hline
\end{tabular}

Médias seguidas da mesma letra não diferem estatisticamente entre si, maiúscula na coluna e minúscula na linha, pelo teste de Tukey ( $>>0,05)$.

Fonte: elaborado pelos autores (2018).

Para L. monocytogenes, os isolados de BAL produziram halos de inibição que variaram entre 19,00 e $21,75 \mathrm{~mm}$. Não houve diferença estatística $(\mathrm{p}<0,05)$ no tamanho dos halos produzidos entre os quatro isolados.

Resultados superiores foram relatados por Andrade et al. (2014), onde avaliaram a atividade antagonista de isolados de Lactobacillus spp. de queijos minas, que produziram halos de inibição $30,53 \mathrm{~mm}$ contra L. monocytogenes. Esta diferença de resultado entre o presente estudo e Andrade et al. (2014) pode ser explicada, devido os isolados serem oriundos de matriz alimentares diferentes.

Quanto a $S$. Enteretidis, os isolados de BAL produziram halos de inibição entre 8,25 e 18,00 mm. O isolado S 14 mostrou-se diferente estatisticamente entre os demais isolados $(\mathrm{p}<0,05)$.

Os halos de inibição produzidos pelos isolados de BAL contra o B. cereus variaram entre 7,50 e 15,00 mm. Não houve diferença estatística no tamanho dos halos produzidos entre os quatros isolados testados. 
Recebido em:

$13 / 09 / 2018$

Aceito em:

$19 / 12 / 2018$

Já, Zhang et al. (2015), avaliaram o efeito antimicrobiano de Lactobacillus plantarum contra duas cepas de B. cereus (ATCC 14579 e HN001) durante a fermentação láctea, e obtiveram halos de inibição de 16,30 e 17,00 mm, respectivamente.

Observa-se na Tabela 4, que o maior halo de inibição produzido foi de 39,75 mm pelo isolados S 13 contra E. coli. Os halos de inibição produzidos pelos quatros isolados de BAL variaram entre 0,00 e 39,75 contra E. coli. Houve diferença estatística no tamanho dos halos produzidos contra E.coli entre os quatro isolados. Resultado inferior foi relatado por Andrade et al. (2014), onde isolados de Lactobacillus spp. de queijos minas, produziram halos de inibição de $35,58 \mathrm{~mm}$ contra E. coli.

Diversos estudos relatam a eficácia das BAL em eliminar ou inibir diversos patógenos, inclusive micro-organismos produtores de biofilmes, como: Staphylococcus spp., Listeria spp., Salmonella spp., Bacillus spp., Pseudomonas spp (YANG et al., 2014; MCCAUGHEY et al., 2016).

As bacteriocinas são peptídeos produzidos pelas BAL, que apresentam atividade antimicrobiana, e sua presença pode ser comprovada através da sua sensibilidade a uma ou mais proteases (MONTVILLE; KAISER, 1993).

Dos quatro isolados de BAL que apresentaram atividade antagonista contra $L$. monocytogenes, $S$. Enteretidis, B. cereus e E. coli, três (75\%) confirmaram produzir bacteriocinas (Tabela 5).

Tabela 5: Sensibilidade dos isolados de BAL (S 07, S 12, S 13, S 14) as proteases proteinase K, pepsina, $\alpha$-quimotripsina, tripsina.

\begin{tabular}{ccccc}
\hline & \multicolumn{4}{c}{ Sensibilidade as proteases } \\
\cline { 2 - 5 } Isolado & Proteinase K & Pepsina & $\alpha$ Quimiotripsina & Tripsina \\
\hline S 07 & + & + & + & + \\
S 12 & + & + & - & + \\
S 13 & + & + & + & - \\
S 14 & - & - & - & - \\
\hline
\end{tabular}

(+) positivo; (-) negativo;

Fonte: elaborado pelos autores (2018).

O isolado S 7 mostrou-se sensível a todas as proteoses testadas, no entanto, os isolados S12 e S13 foram sensíveis a três enzimas.

Segundo Arauz et al. (2009), a sensibilidade a mais de uma enzima sugere produção de diferentes bacteriocinas, porém, não é possível constatar, qual bacteriocina é produzida através desta técnica. Schittler (2012), isolou 307 BAL de leite in natura e avaliou a atividade antimicrobiana contra L. monocytogenes, destes, apenas $28(9,12 \%)$ isolados apresentaram atividade bacteriocinogênica. 
Recebido em:

$13 / 09 / 2018$

Aceito em:

$19 / 12 / 2018$

\subsection{Sensibilidade à antibióticos clínicos}

Por se tratar de BAL, cujo sua identificação genômica não tenha sido realizada e por serem micro-organismos com potencial aplicação em alimentos, como bioconservante, se faz necessário avaliar alguns fatores de virulência, como a sensibilidade a antibióticos.

Os quatro isolados de BAL bacteriocinogênicos foram sensíveis aos antibióticos ampicilina, penicilina, vancomicina, tetraciclina. A média dos tamanhos dos de halos de inibição formados foram de 27,00, 17,00, 25,00 e 30,00 mm para ampicilina, penicilina, vancomicina e tetraciclina, respectivamente. No entanto, estudo de Schittler (2012), verificou que dos 16 isolados de Enterococcus faecium apresentaram sensibilidade de $94 \%, 81 \%, 62 \%$ e $100 \%$ para os antibióticos ampicilina, tetraciclina, penicilina e vancomicina, respectivamente. A diferença de resultado quanto a sensibilidade a antibióticos pode ser explicada quanto ao isolamento ter sido de matrizes alimentares diferentes, desta forma apresentam características fenotípicas relacionados ao habitat.

\section{CONCLUSÃO}

As salsichas vendidas a granel, apresentaram as maiores contagens microbianas, do que as salsichas vendidas em embalagem à vácuo. Inclusive, as salsichas vendidas a granel, comercializadas por uma marca, estavam em desacordo com os padrões microbiológicos estabelecidos para Staphylococcus coagulase positiva e coliformes termotolerantes.

Podemos inferir que, o perfil microbiano da salsicha é variável, estando diretamente relacionada com a qualidade na produção e comercialização do produto.

Quanto aos isolados de BAL, quatro apresentaram atividade antagonista contra $L$. monocytogenes, $S$. Enteretidis, B. cereus e E. coli, das quais, três confirmaram a produção de bacteriocinas. Os isolados bactericinogênicos foram sensíveis aos antibióticos clínicos testados, ou seja, são considerados bons candidatos para estudos complementares de utilização e aplicação na bioconservação de alimentos.

Ressalta-se a necessidade de treinamento dos manipuladores quanto as Boas Práticas de Fabricação, para assegurar a qualidade microbiológica e a saúde do consumidor.

\section{REFERÊNCIAS}

ALCÂNTARA, M. A. et al. Avaliação do perfil microbiológico de salsichas tipo "hot dog" comercializadas em embalagens a vácuo e a granel. Veterinária em Foco, v. 10, n. 1, 2012.

ANDRADE, C. R. G. et al. Propriedades probióticas in vitro de Lactobacillus spp. isolados de queijos minas artesanais da Serra da Canastra-MG. Arquivo Brasileiro de Medicina Veterinária e Zootecnia, v. 66, n. 5, p. 1592-1600, 2014.

APHA - AMERICAN PUBLIC HEALTH ASSOCIATION. COMMITTEE ON MICROBIOLOGICAL FOR FOODS. Compendium of methods for the microbiological examination of foods. 4.ed. Washington: American Public Health Association, 2001 
ARAUZ, L. J. et al. Nisin biotechnological production and application: A review. Trends in Food Science and Tecnology, v. 20, p. 146-154, 2009.

BAÚ, T. R.; DE ABREU, C. D; DA TRINDADE, A. A. Avaliação da qualidade química e microbiológica de salsichas tipo Viena. Revista do instituto Adolfo Lutz, v. 71, n. 1, p. 207-210, 2012.

BRASIL. MINISTÉRIO DA AGRICULTURA, PECUÁRIA E ABASTECIMENTO. Instrução Normativa $n^{\circ}$ 62, de 26 de agosto de 2003. Diário Oficial da União. Brasília, 18 de setembro de 2003.

BRASIL. MINISTÉRIO DA SAÚDE. AGÊNCIA NACIONAL DE VIGILÂNCIA SANITÁRIA. Resolução $\operatorname{RDC~}^{\circ}{ }^{12}$, de 2 de janeiro de 2001. Diário Oficial da União. Brasília, 2 de janeiro de $2001 b$.

CARVALHO, A. C. F. B. et al. Presença de micro-organismos mesófilos, psicrotróficos e coliformes em diferentes amostras de produtos avícolas. Arquivos do Instituto de Biologia, v. 72, n. 3, p. 303-307, 2005.

CHAMPAGNE, C. P. et al. Psychrotrophs in dairy products: their effects and their control. Critical Reviews in Food Science \& Nutrition, v. 34, n. 1, p. 1-30, 1994.

COSTA, C. D. R da S. Importância de Staphylococcus spp. Produtores de enterotoxinas em alimentos. 2008. 34f. Monografia (Especialista em Microbiologia) -Universidade Federal de Minas Gerais, Belo Horizonte, 2008.

CUNHA, M. B. et al. Qualidade físico-química e microbiológica de diferentes marcas de salsichas hot dog. In: CONGRESSO ESTADUAL DE INICIAÇÃO CIENTÍFICA E TECNOLÓGICA, 6. 2017, Urutaí, Anais... Urutaí: IF Goiano, 2017.

D'AIMMO, M.R. et al. Antibiotic resistance of lactic acid bacteria and Bifidobacterium spp. isolated from dairy and pharmaceutical products. International Journal of Food Microbiology, v. 115, p. 35-42, 2007

DINIZ, F. R. LAGO, N. C. M. R. de. Análises microbiológicas em salsichas tipo hot dog e presuntos em embalagens a vácuos e a granel avaliando as boas práticas de manipulação de alimentos em supermercados de Ribeirão Preto - São Paulo, Brasil. In: ENCONTRO DE INICIAÇÃO CIENTÍFICA DO CENTRO UNIVERSITÁRIO BARÃO DE MAUÁ, 10, 2016, Ribeirão Preto, Anais... Ribeirão Preto: Centro Universitário Barão de Mauá, 2016.

EHRAMPOUSH, M. H. et al. Microbiological Quality of Sausage during Slicing at Food Retail Stores in Shiraz, Iran. International Journal of Nutrition Sciences, v. 2, n. 1, p. 21-26, 2017.

FERNANDES, E. N. et al. Enumeração e atividade antagonista de bactérias ácido láticas isoladas de iogurtes brasileiros. Revista Cientifica Univiçosa, Viçosa, v.7, 2015. 
FERRACIOLI, V. R. Avaliação da qualidade de salsichas do tipo Hot Dog durante o armazenamento. 2012. 115f. Dissertação (Mestrado em Engenharia de Processos Químicos e Bioquímicos) Centro universitário do Instituto Mauá de Tecnologia, São Caetano do Sul, São Paulo, 2012.

FLEMING, H. P.; ETCHELLS, J. L.; COSTILOW, R. N. Microbial inhibition by an isolate of Pediococcus from cucumber brines. Applied Microbiology, v. 30, n. 6, p. 1040-1042, 1975.

GASPAR, P. et al. From physiology to systems metabolic engineering for the production of biochemicals by lactic acid bacteria. Biotechnology Advances, v. 31, n. 6, p.764-788, 2013.

ISO International Standard Organization. ISO 4833:2013. Microbiology of food and animal feeding stuffs - Horizontal method for the enumeration of microorganisms a 30 degrees $\mathrm{C}$ by the pour plate technique. 1 th ed, 2013.

ISO International Standard Organization. ISO 6579:2017. Microbiology of food and animal feeding stuffs - Horizontal method for the detection of Salmonella spp. 1th ed, 2017.

LIMA, A. C. F. et al. Efeito do uso de probiótico sobre o desempenho e atividade de enzimas digestivas de frangos de corte. Revista Brasileira de Zootecnia, v.32, n.1, p.200-207, 2003.

MCCAUGHEY, L. C. et al. Efficacy of species-specific protein antibiotics in a murine model of acute Pseudomonas aeruginosa lung infection. Scientific reports, v. 6, p. 30201, 2016.

MESSAOUDI, S. et. al. Lactobacillus salivarius: Bacteriocin and probiotic activity. Food Microbiology, v. 36, n. 2, p. 296-304, 2013.

MONTEVILLE, T. J; KAISER, A. Antilisterial proteins classification, momenclature, diversity and relationship to bacteriocins, In: HOOVER, D. G.; STEENSON, L. R. (ed.), Bacteriocins of lactic and bacteria. New York, Academic Press, p 1-22, 1993.

NOBRE, F. S. D. Identificação de microrganismos patógenos, deteriorantes e bactérias láticas em linguiça suínas e avaliação do potencial efeito probiótico. 2011. Tese de Doutorado. UFLA, 2011.

OLIVEIRA, D.T. et al. Psicrotróficos na indústria de laticínios. XV Amostra de Iniciação Científica. UNICRUZ, RS. 2012.

PEHRSON, M. E. de S. F. Avaliação da atividade antimicrobiana de substâncias sintetizadas por cepas de Lactobacillus sp. que apresentam propriedades probióticas. 2013 Tese de Doutorado. Universidade de São Paulo.

RENYE, J. A. et al. Caracterization of antilisterial bacteriocins produced by Enterococcus faecium and Enterococcus durans isolates from Hispanic-style cheeses. Journal of Industrial 
Microbiology e Biotechnology, v. 36, n. 2, p. 261-8, 2009.

SADE, E. 2011. Leuconostoc Spoilage of Refrigerated, packaged foods. Dissertação (mestrado). Faculty of Veterinary Medicine, University of Helsinki, Finland.

SAEKI, E. K.; MATSUMOTO, L. S. Contagem de mesófilos e psicrotróficos em amostras de leite pasteurizado e UHT. Revista do Instituto de Laticínios Cândido Tostes, v. 65, n. 377, p. 29-35, 2010.

SCHITTLER, L. Isolamento e caracterização fenotípica e molecular de bactérias ácido láticas bacteriocinogênicas em leite in natura da região oeste de Santa Catarina. 2012. 92f. Tese (Doutorado em Ciência e Tecnologia Agroindustrial) - Universidade Federal de Pelotas. Pelotas. Rio Grande do Sul, 2012.

SILVA, M. C. da. Avaliação da qualidade microbiológica de alimentos com a utilização de metodologias convencionais e do sistema simplate. 2002. 87f. Dissertação (Mestrado em Ciências). Universidade de São Paulo. 2002.

SOUSA, I. S. et al. Monitorização microbiológica em produtos de charcutaria cozidos, fatiados em talhos. Instituto Nacional de Saúde. v.2 n 12, p. 49-51, 2016.

VALENTE, M. dos A. S. Q. Avaliação da atividade antibacteriana de Adansonia digitata l. e Euclea natalensis a.dc: sua potencial aplicação num produto cárneo. 2017. Dissertação de Mestrado em Segurança Alimentar, Faculdade de Medicina Veterinária, Universidade de Lisboa, Lisboa, 2017.

VERCAMMEN, A. et al. Shelf-life extension of cooked ham model product by high hydrostatic pressure and natural preservatives. Innovative Food Science \& Emerging Technologies, v. 12, n. 4, p. 407-415, out. 2011.

YANG, S. C., et al. Antibacterial activities of bacteriocins: Application in foods and pharmaceuticals. Frontiers in Microbiology, v. 5, n. 241. P. 1- 10, 2014.

ZHANG, Z. et al. Antagonistics against pathogenic Bacillus cereus in milk fermentation by Lactobacillus plantarum ZDY2013 and its anti-adhesion effect on Caco-2 cells against pathogens. Journal of dairy science, v. 99, n. 4, p. 2666-2674, 2016 